\title{
ОЦЕНКА ТРАНСФЕРТОВ ВРЕМЕНИ ВНУТРИ ДОМОХОЗЯЙСТВ
}

\author{
ИРИНА КАЛАБИХИНА, ЖАДРА ШАЙКЕНОВА
}

\begin{abstract}
Статья посвящена исследованию трансфертов времени между членами российских домашних хозяйств, определению роли женщин и мужчин в производстве и потреблении домашних услуг, а также оченке «невидимого» для рыночной экономики домачнего труда. Исследование основано на методологии, разработанной в рамках глобального проекта ООН «Национальньле трансфертнье счета». На эмпирических данных изучена асимметрия в распределении домашних обязанностей между мужчинами и женщинами, показано, что женщины за сутки, в среднем, производят почти на 3 часа больше временных трансфертов по сравнению с мужчинами. Таким образом, женщины с 20 до 80 лет являются производителями домашних услуг для всех членов семьи. С учетом работь по дому, 8-часовой рабочий день женщин на рынке труда ежедневно может продлеваться почти на 40\%. Традиционные выводы о большем вкладе женщин как в экономику заботы, так и в ведение домашнего хозяйства подкреплены оригинальными выводами о наличии возрастных пиков у мужчин $u$ женщин в производстве $и$ потреблении трансфертов времени; построена матрица межпоколенческих и межгендерных трансфертов времени. Оченка «невидимого» для рыночной экономики продукта составила 25,3\% ВВП в 20142.
\end{abstract}

Ключевые слова: трансферты времени, бюджеты времени, неоплачиваемый труд, гендерное неравенство, домашний труд, экономика заботы.

\section{ВВЕДЕНИЕ}

Время - один из самых ценных ресурсов, которым обладает человек. Обычно экономисты исследовали время, затрачиваемое индивидами на рынке труда, игнорируя тот факт, что большая часть суточного фонда времени распределяется за пределами рынка труда. Так, разработанная во второй половине прошлого века система национальных счетов (СНС) претендует на предоставление всеобъемлющих сводных данных об экономических показателях страны. Миллионы долларов выделяются на сбор регулярных статистических данных о валовом внутреннем продукте (ВВП). ВВП и статистика занятости в настоящее время рассматриваются правительствами и экономистами как основные переменные в анализе экономической и социальной политики. Официальная статистика классифицирует людей как «экономически активных» только с точки зрения их вклада в ВВП. Эти статистические данные игнорируют участие людей в экономике домохозяйства. Человек определяется как «экономически не активный», если он занимается только «домашними обязанностями». Почти все необходимые и затратные по времени, но неоплачиваемые, виды экономической деятельности домохозяйств исключаются из национальных счетов.

ИРИНА ЕВГЕНЬЕВНА КАЛАБИХИНА (ikalabikhina@yandex.ru), МОСКОВСКИЙ ГОСУДАРСТВЕННЫЙ УНИВЕРСИТЕТ иМЕНИ М.В. ЛОМОНОСОВА, РОССИЯ.

ЖАДРА КАНАТОВНА ШАЙКЕНОВА (shaikenova@mail.ru), МОСКОВСКИЙ ГОСУДАРСТВЕННЫЙ УНИВЕРСИТЕТ имЕНИ М.В. ЛОМОНОСОВА, РОсСия.

СТАТЬЯ ПОСТУПИЛА В РЕДАКЦИЮ В ОКТЯБРЕ 2018 Г. 
Таким образом, неоплачиваемая домашняя работа является невидимой и часто считается экономически бесполезной. Учет производительных затрат времени, перераспределяемых между членами домашнего хозяйства вне рынка, позволяет получить более полную оценку потребностей представителей отдельных групп населения, что дает возможность выстроить социальную политику, которая лучше отвечает его реальным потребностям. Учет неоплачиваемого труда домашних хозяйств показывает, как именно распределяются обязанности заботы о пожилых, детях и других уязвимых группах населения между государством и семьей. А рыночная оценка времени, расходуемого в рамках домашнего хозяйства, дает возможность увидеть более полную картину и на реальных данных показать не только роль домохозяйств в создании продуктов и услуг, но также перераспределение нагрузки между членами домашнего хозяйства, которое, в свою очередь, влияет на принятие демографических решений.

Вопрос оценки неоплачиваемого домашнего труда привлекает внимание исследователей еще с первой половины XX века. Экономисты долгое время утверждали, что игнорирование товаров и услуг, создаваемых внутри домохозяйств, приводит к предвзятости в различных областях экономического анализа. Митчелл, Кузнец, Кларк [Mitchell et al. 1921; Kuznets 1944; Clark 1958] отметили, что национальный доход значительно недооценивается, если не учитывать производительную деятельность домашних хозяйств. Смещение оценок производимого в стране продукта при игнорировании роли домохозяйств также подтверждается и теорией распределения времени Г. Беккера [Becker 1965]. Теория распределения времени создавалась с целью дать общее понимание принципов распределения индивидами времени между оплачиваемой и неоплачиваемой деятельностью. Беккером была построена модель потребительского выбора, в которой индивиды рассматривались не только как потребители благ, но также и как производители, использующие время наряду с другими ресурсами при производстве благ и услуг. Данная модель позволила понять, чем обусловлено решение индивидов относительно времени, посвящаемого труду в рамках домохозяйства, и сколько стоит это время.

Советские экономисты в своих работах также подчеркивали важность учета времени, расходуемого на производство товаров и услуг внутри домашних хозяйств. Так, С.Г. Струмилин [1957] выдвигает положение об общественной стоимости воспроизводства рабочей силы, подчеркивая, что о ней нельзя составить представление без учета домашнего труда. Г.А. Пруденским [1972] была разработана классификация видов деятельности, которая включала рабочее и внерабочее время, которое, в свою очередь, делилось на внерабочее время, связанное с работой; время удовлетворения физиологических потребностей; время на домашний труд и удовлетворение других бытовых потребностей и, наконец, собственно свободное время. Г.А. Пруденский подчеркивал, что не только рабочее, но и внерабочее время (домашний труд, удовлетворение физиологических потребностей, образование, общественная деятельность и отдых) имеет важное значение для функционирования общества. Исследования советского времени показали, что домашнему труду отводится значимая часть времени населения. Так, согласно данным исследований бюджетов времени семей рабочих, проводившихся в СССР в период 1922-1934 гг., время, расходуемое на домашний труд, 
составляло 12 часов в неделю для мужчин и 36,5 часа для женщин [Социология в России 1996]. В 1920-30-е годы прошло около 50 обследований бюджетов времени, затем наблюдался спад в 1940-1950-е годы (14 обследований), подъем в 1960-1970-е годы (109 обследований) и вновь спад в 1990-е (менее 10 обследований). Основные обследования проходили в Институте социологии РАН и в ЦСУ/ Госкомстате РСФСР [Патрушев, Артемов, Новохацкая 2001]. Последние обследования бюджетов времени силами государственного статкомитета в России были в 1990 и 2010 гг. - с большим интервалом и по разным методикам [Итоги... 2010].

Учет неоплачиваемого труда и в современной России остается одной из важных задач. По мнению Г.П. Гвоздевой, в результате игнорирования неоплачиваемого труда происходит недооценка общего общественного продукта, а экономический вклад многих людей, особенно женщин, не получает должного признания и вознаграждения [Гвоздева 2000].

При анализе неоплачиваемого труда в 2000-е годы многие исследователи основываются на данных Российского мониторинга экономического положения и здоровья населения НИУ ВШЭ (РМЭЗ). В РМЭЗ объединены наблюдения за 22 года проведения мониторинга, начиная с 1994 г., собрана информация о структуре доходов и расходов, материальном благосостоянии, работе и миграционном поведении, здоровье и структуре питания, об образовательном поведении и досуге и др. ${ }^{1}$

Большое внимание в рамках анализа неоплачиваемого труда в России уделяется распределению обязанностей по ведению домашнего хозяйства между мужчинами и женщинами. К примеру, в работе [Deloach, Hoffman 2002] авторы анализируют распределение домашних обязанностей между мужчинами и женщинами и приходят к выводу о существовании неравенства: российские женщины затрачивают гораздо больше времени в рамках ведения домашнего хозяйства и меньше времени на оплачиваемую работу по сравнению с мужчинами. Проблема неравенства в распределении обязанностей в рамках ведения домашнего хозяйства также рассматривается в работе Лефмарк [Löfmark 2007], где автор на основе данных РМЭЗ выявляет ряд факторов, которые влияют на распределение домашних обязанностей между партнёрами. Так, по мнению автора статьи, на распределение обязанностей в рамках ведения домашнего хозяйства значимое влияние оказывает наличие детей в возрасте до 12 лет. Кроме того, есть ряд параметров, которые большее влияние оказывают на долю работ по дому, выполняемую женщинами, и меньше влияют на долю мужчин, в частности, доход домашнего хозяйства и доля каждого из партнёров в нем. Также интересным представляется результат, согласно которому уровень образования мужчин значимо влияет на распределение домашних обязанностей между партнёрами, в то время как уровень образования женщин такого влияния не оказывает.

Современные оценки продукта, производимого внутри домашних хозяйств, показывают, что неоплачиваемые затраты времени составляют значимую часть ВВП стран. Так, в работе Хэмдэда [Hamdad 2003] было рассчитано, что рыночная стоимость неоплачиваемой работы в Канаде в 1998 г. составила 297 млрд долл. США или около 33\%

\footnotetext{
${ }^{1}$ URL: https://www.hse.ru/rlms/ (дата обращения: 19.11.2018).
} 
ВВП Канады за этот год. По оценкам американских ученых [Landefeld, Fraumeni, Vojtech 2009], доля неоплачиваемого труда в США составила 20\% от ВВП за 2004 г. Для европейских стран данный показатель колеблется от 24\% в Латвии до 57\% в Германии [Giannelli, Mangiavacchi, Piccoli 2011].

Полученные различными авторами оценки стоимости неоплачиваемого труда заставляют задуматься над тем, как именно распределяются продукты и услуги, производимые вне рынка. В соответствии с Международной классификацией видов деятельности для статистики использования времени [ICATUS 2016], все время, расходуемое внутри домохозяйства, можно разделить на следующие основные группы:

- $\quad$ время, расходуемое на заботу о близких (экономика заботы):

○ забота о пожилых / воспитание детей в рамках домашнего хозяйства;

○ забота о пожилых / воспитание детей в рамках расширенного домашнего хозяйства;

- время, расходуемое на ведение домашнего хозяйства;

- волонтерская работа на локальную общину.

Неформальный уход является жизненно важным компонентом межпоколенческих трансфертов, с точки зрения как воспитания детей, так и поддержки пожилого населения. Экономика заботы представляет собой отдельную огромную область исследования, включающую вопросы воспитания детей и роли родителей на различных этапах развития ребенка, вопросы обмена финансовыми и временныли трансфертами между взрослыми детьми и их пожилыми родителями и многое другое. Именно по этой причине в данном исследовании разграничено время, расходуемое на заботу о близких, и время, расходуемое населением на ведение домашнего хозяйства. Все эти временные затраты на данный момент не получают рыночной оценки, однако занимают значительную часть жизни каждого человека. В связи с этим рассмотрим основные вопросы, которые встают перед исследователями, и методики, которые ими используются в части оценки неоплачиваемого домашнего труда индивидов.

При анализе времени, затрачиваемого на ведение домашнего хозяйства и заботу о близких, почти все авторы, независимо от фокуса исследования, подчеркивают важность гендерных ролей в распределении обязанностей в рамках домохозяйства. Во многих странах бремя домашней работы остается главным образом на женских плечах, несмотря на растущую активность женщин на рынке труда. Хохшильд [Hochschild 1989: 322] ввел термин «застопорившаяся революция», чтобы описать ситуацию, при которой более высокий уровень занятости женщин не приводит к росту ответственности мужчин за ведение домашнего хозяйства и заботу о детях и престарелых родственниках. Макдональд утверждал, что гендерная революция не завершена, пока гендерное равенство не распространится и в семье [McDonald 2000]. Баланс гендерного неравенства в домохозяйстве и в общественных институтах сменяется балансом гендерного равенства в них. Но данная смена проходит болезненно и в социальном, и в демографическом контексте из-за отставания распространения гендерного равенства в домохозяйстве, как свидетельствует концепция гендерного перехода, согласно которой, несмотря на растущую экономическую активность женщин, роль мужчин в выполнении обязанностей по дому не меняется вплоть до последней (третьей) стадии гендерного перехода [Калабихина 2011: 42- 
48]. Хотя эта ситуация практически универсальна, степень гендерных различий в распределении труда варьируется в разных странах в соответствии с режимом социального обеспечения, семейной политикой и политикой в области занятости, системой налогообложения и пособий, а также социальными нормами. Гендерное неравенство в распределении времени также заметно меняется в течение жизни человека. Несколько исследований [Anxo et al. 2007; Apps, Rees 2005] показали, что значимые гендерные различия в распределении времени в разных странах связаны со сроками наступления ключевых событий в течение жизненного цикла человека. К примеру, возраст, в котором юноша/девушка покидает родительский дом, влияет не только на образование союзов и рождение детей, но и на жизнь его/её родителей. Активная роль женщин как в рамках ведения домашнего хозяйства, так и на рынке труда создает для них так называемое «двойное бремя». Гендерный разрыв в распределении времени может зависеть от институционального и социального контекста, в частности, от характеристик системы отпусков по уходу за ребенком, наличия и стоимости услуг по уходу за детьми или нуждающимися взрослыми, наличия и распространенности гибких форм занятости [Lewis 1992]. Женщины больше мужчин склонны к неполной занятости (рисунок 1), которая позволяет им выполнять домашние обязанности, не уходя с рынка труда.

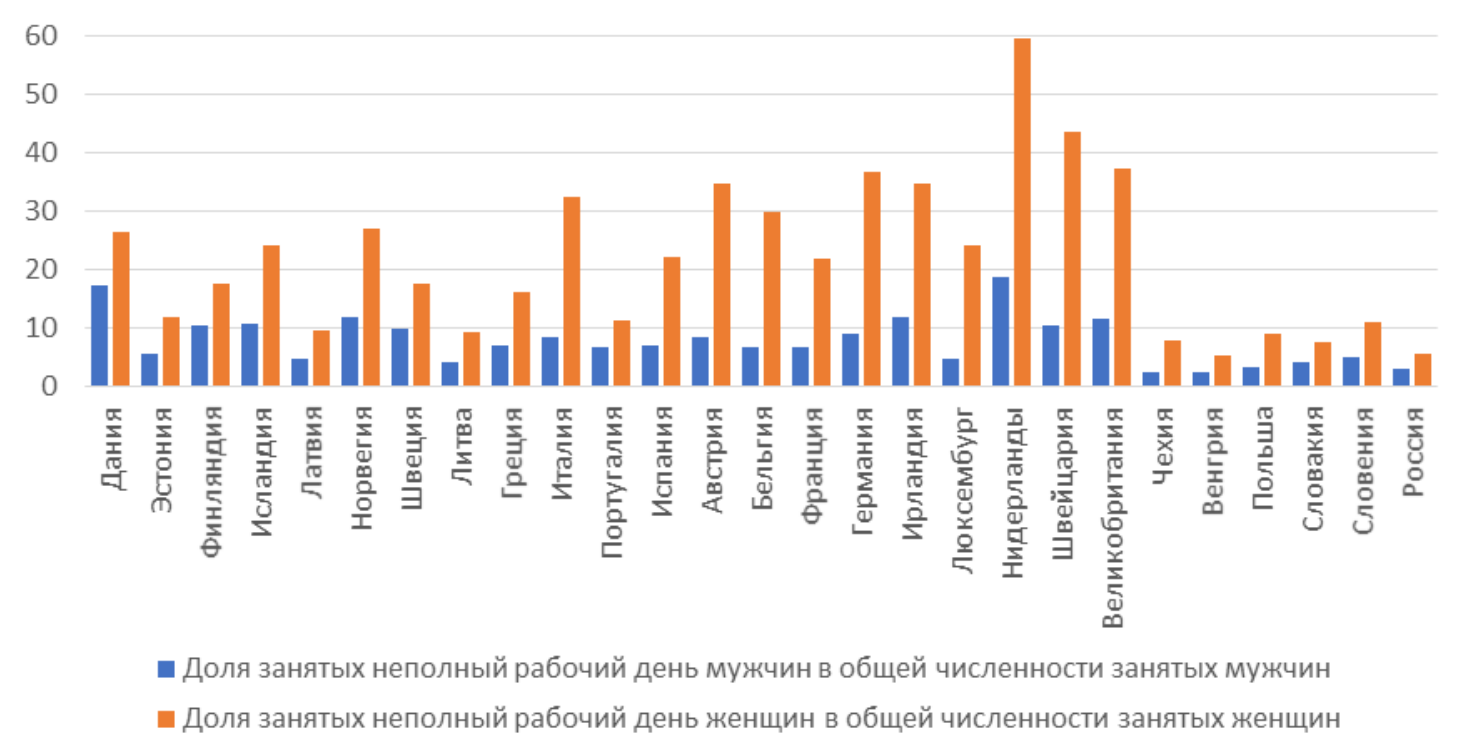

\section{Рисунок 1. Доля мужчин и женщин, занятых неполный рабочий день, в некоторых странах, 2016, \%}

Источник: Рассчитано и составлено авторами на основе данных OЭCP. URL:

http://stats.oecd.org/BrandedView.aspx?oecd_bv_id=lfs-data-en\&doi=data-00305-en (dama

обрашения:12.03.2018).

Время, затрачиваемое на неоплачиваемую работу, значительно варьируется в зависимости от страны. К примеру, итальянки, в среднем, тратят на домашние дела на всех этапах жизненного цикла от 12 до 51 часа в неделю - намного больше, чем шведские женщины, которые уделяют ведению домашнего хозяйства от 8 до 29 часов в неделю. Женское время, потраченное на неоплачиваемую работу, увеличивается с образованием брачных союзов. Кроме того, вполне ожидаемым стало увеличение затрат времени женщин при наличии детей дошкольного возраста. В целом женщины сокращают свое участие в 
ведении домашнего хозяйства только тогда, когда они живут одни на заключительном этапе своего жизненного цикла. Мужчины обычно тратят меньше времени на работу по дому, более того, затраты времени на ведение домашнего хозяйства остаются довольно низкими на протяжении практически всей жизни. Количество часов, которые они тратят на работу по дому, значительно возрастает только после выхода на пенсию. Кроме того, было выявлено, что мужчины старше 60 лет уделяют больше времени неоплачиваемой работе, чем молодые люди, даже если у последних есть дети дошкольного возраста [Anxo et al. 2007].

Во всех странах на всех этапах жизненного цикла существует гендерный разрыв во времени, посвященном домашним делам. Во Франции и в Италии гендерный разрыв увеличивается с образованием брачных союзов. Гендерные различия чрезвычайно велики для итальянцев на всех этапах жизненного цикла, в частности в случае семейной пары с детьми: итальянские женщины работают в среднем на 40 часов в неделю больше, чем их мужья, тогда как в Швеции этот разрыв составляет всего 11 часов. Эти различия между странами объясняются, в первую очередь, существующими социальными нормами, семейной политикой государства, режимами занятости. Благодаря активной политике в установлении равенства между мужчинами и женщинами в сфере занятости, Швеция 2 имеет на данный момент самый низкий гендерный разрыв в распределении времени, тогда как Италия с более традиционной моделью семьи - самый высокий [Vargha, Gál, CrosbyNagy 2017].

Тенденции, выявленные исследователями в распределении домашних обязанностей между членами семьи, присущи и российским домашним хозяйствам. В связи с этим интересным представляется анализ распределения времени, расходуемого женщинами и мужчинами на ведение домашнего хозяйства и заботу о близких в России. Новизна данного исследования заключается в том, что впервые на российских данных мы используем метод Национальных счетов трансфертов времени (NTTA), который позволяет построить половозрастные профили производства и потребления внутридомохозяйственных трансфертов времени. Несмотря на то, что показатели Национальных счетов трансфертов времени в последние годы стали активно используемым инструментом анализа объемов неоплачиваемого труда во многих западных странах [Albertini, Kohli, Vogel 2007; Dukhovnov, Zagheni 2015; Leopold, Raab 2010], расчетов на основе российских данных на данный момент нет. Мы также построим матрицу межпокленных и межгендерных трансфертов для определения связей между производителями и потребителями времени: кто для кого производит больше временных трансфертов в домохозяйствах.

Данная работа структурирована следующим образом: в первом разделе рассматривается использованная методология оценки трансфертов времени, во втором дается описание данных, в третьем разделе приведены основные результаты изучения распределения «домашнего» времени в России и сделана оценка его рыночной стоимости.

\footnotetext{
2 Швеция является одной из стран с самым низким общим гендерным разрывом среди всех стран мира и находится на втором месте по величине GEM (Gender Empowerment Measure Index) [Human Development Report 2006].
} 


\section{МЕТОДОЛОГИЯ ОЦЕНКИ ТРАНСФЕРТОВ ВРЕМЕНИ}

\section{Способы рыночной оценки времени, посвященного ведению домашнего хозяйства и заботе о близких}

На данный момент нет единого подхода к рыночной оценке производимого внутри домашних хозяйств продукта. Согласно Фицджеральду [Fitzgerald 1990], существует два основных подхода к оценке продукта, производимого внутри домохозяйств:

1. прямой;

2. косвенный:

a) оценка альтернативных издержек;

b) оценка функциональных издержек.

Прямой подход предполагает получение рыночной оценки объема товаров и услуг, который был произведен домашним хозяйством в отчетном периоде. Основная предпосылка данного подхода состоит в том, что, в среднем, качество продукта домохозяйств и рыночных компаний одинаково. Однако данное предположение неочевидно. С одной стороны, фирмы по определению нанимают «профессионалов» для выполнения своей работы. С другой стороны, домашние хозяйства потребляют собственные продукты и услуги и, следовательно, имеют прямой стимул для поддержания качества. Кроме того, прямой способ оценки довольно затруднителен с точки зрения доступности данных. В своей статье Фицджеральд [Fitzgerald 1990] основывается на данных собственного опроса, в котором он собрал данные не только по затратам времени на выполнение домашних обязанностей, но также по объему произведенного в результате продукта. Данный подход действительно имеет ряд достоинств, в частности, он позволяет учесть затраты не только трудовых ресурсов, но и капитальных, которые заложены в рыночной цене продукта. Однако производительность домашних хозяйств не равна производительности рыночных фирм. Как правило, профессионалы выполняют работу гораздо быстрее членов домохозяйств, хотя такие виды деятельности, как уход за ребенком или выполнение работы по дому, требующей особых знаний владельца дома, эффективнее выполняются внутри домашнего хозяйства [Fitzgerald 1990].

Косвенные методы оценки продукта домохозяйств заключаются в получении рыночной оценки времени, затрачиваемого членами домохозяйств. В случае метода альтернативных издержек рыночной ценой единицы времени выступает заработная плата члена домашнего хозяйства, выполнившего работу по дому. Данный метод основывается на предположении, что человек, выполняя свои домашние обязанности, полностью или частично отказывается от рыночной занятости, которая бы приносила ему доход в размере заработной платы.

При оценке методом функциональных издержек все время делится по видам деятельности (мытье посуды, уборка помещений и др.) и для каждого вида деятельности определяется своя рыночная цена единицы затраченного времени. В научной литературе выделяют три способа оценки времени, затрачиваемого на тот или иной вид деятельности [Webber 2017]: 
- универсальная оценка;

- специализированная оценка;

- гибридная оценка.

При универсальной оценке в качестве стоимости единицы времени используется заработная плата домработниц, выполняющих практически всю работу по дому. Специализированная оценка предполагает использование рыночных зарплат соответствующих специалистов: время, затраченное на мытье посуды, оценивается по ставке посудомойки; работы в саду - по ставке садовника и так далее. Гибридная оценка сочетает в себе первые две.

Однако и косвенный метод оценки продукта домашних хозяйств также имеет свои недостатки. Оценка по альтернативной стоимости, как правило, приводит к завышению стоимости домашнего труда, особенно в случае высококвалифицированных членов домашнего хозяйства. Функциональная оценка основывается на том же предположении, что и прямая оценка стоимости домашнего труда, a именно на равенстве производительности членов домохозяйств и специалистов (домработниц или специалистов в отдельных областях), что, как показано в работе [Fitzgerald 1990], неверно. Различные подходы в оценке дают различный результат. Так, труд американских домохозяйств при оценке по альтернативной стоимости составляет 60\% от ВВП, при специализированной оценке - 24\%, в случае универсальной оценки - 20\% [Landefeld, Fraumeni, Vojtech 2009].

\section{Методология оценки трансфертов времени}

В связи с пониманием того факта, что ведение домашнего хозяйства занимает значительную часть времени и усилий, перед исследователями встал вопрос: как распределяется продукт, производимый внутри домашних хозяйств? Кто является основным производителем, а кто потребителем продуктов ведения домашнего хозяйства? Пытаясь ответить на эти и многие другие вопросы, связанные с распределением трансфертов времени, Дж. Донховер [Donehower 2014] разработала методологию расчета Национальных счетов трансфертов времени (NTTA; далее - Методология) в рамках проекта $\mathrm{OOH}$ «Национальные трансфертные счета» (NTA). Оценка временных трансфертов согласно методологии NTTA состоит из нескольких шагов:

1. определить источник информации;

2. определить список видов деятельности, относящихся к производительной деятельности внутри домашних хозяйств;

3. распределить затраты времени между потребителями временных трансфертов;

4. определить уровни рыночных заработных плат в соответствии с видами деятельности для получения рыночной оценки затрат времени.

\section{1. Определение источника информации}

В Методологии закреплены основные критерии отбора источника информации:

- опрос должен быть репрезентативен на национальном уровне;

- информация должна быть представлена в разрезе каждого члена домашнего хозяйства; 
- должна содержаться информация об основных характеристиках каждого индивида (возраст, пол);

- должна содержаться информация о распределении времени как в будние, так и в выходные дни;

- должна содержаться информация о распределении времени хотя бы одного члена домашнего хозяйства;

- общее количество распределяемых часов должно стремиться к 24.

\section{2. Определение списка видов деятельности, относящихся к производительной}

\section{деятельности домашних хозяйств}

В расчет трансфертов времени включаются те виды деятельности, которые были бы включены в национальный доход, если бы они выполнялись за заработную плату, а не за счет нерыночной рабочей силы. Один из способов определить, соответствует ли данный вид деятельности этому стандарту, - критерий третьей стороны (“third party criterion”), т.e. может ли операция быть выполнена кем-то другим за плату [Reid 1934: 424]. Таким образом, время, потраченное на сон, прием пищи, спорт и досуг, не будет учтено в расчете, однако любые операции по ведению домашнего хозяйства или уходу будут включены в расчет.

Согласно методологии NTTA в расчет включается лишь время, затраченное на производительную деятельность домашних хозяйств, не включенную в ВВП. Так, в расчет не включается время, затраченное на производство в семейных предприятиях; неоплачиваемый труд, который уже включен в расчет ВВП, к примеру, ведение собственного подсобного хозяйства ${ }^{3}$.

Таким образом, общий список видов деятельности, которые должны быть включены в расчет трансфертов времени согласно Методологии, следующий:

1. уборка;

2. стирка белья (включая шитье, ремонт одежды);

3. кулинария (приготовление пищи и напитков);

4. обслуживание и ремонт;

5. уход за газонами и садами;

6. управление домохозяйством (включая финансы, планирование и др.);

7. уход за животными (не ветеринарный уход);

8. покупка товаров и услуг;

9. уход за детьми;

\footnotetext{
${ }^{3}$ В границы производства (при расчете ВВП) включается также производственная деятельность домашних хозяйств. Она охватывает производство всех товаров независимо от того, проданы они или нет, включая сельскохозяйственную продукцию, полученную в личных подсобных хозяйствах, строительство своими силами и различные услуги, реализованные на сторону, в том числе торговые, посреднические и др. Услуги, производимые домашними хозяйствами для собственного потребления (домашние услуги), не включаются в границы производства, кроме условно исчисленной стоимости услуг, предоставленных в связи с проживанием владельцев в собственных жилищах. URL: http://www.gks.ru/free_doc/new_site/vvp/metod.htm (дата обращения: 10.06.2018).
} 
10. уход за пожилыми;

11. передвижения (связанные с деятельностью по уходу и закупкой товаров и услуг).

В данном исследовании рассмотрены трансферты времени, распределяемые в пределах одного домашнего хозяйства. Таким образом, виды деятельности, классифицируемые как волонтёрство или оказание неоплачиваемой помощи другим домохозяйствам, в рамках данного исследования не рассматриваются. Такое ограничение связано с неопределенностью выгодополучателя при распределении произведенных трансфертов времени. В методологии нет четких рекомендаций, как именно распределять временные ресурсы в таком случае [Donehower 2014], потому этот вопрос требует дополнительной проработки и выявления ключевых характеристик домашнего хозяйства и индивидов для корректного распределения трансфертов времени между потребителями, что выходит за рамки текущего исследования. Основываясь на Методологии, нами были отобраны виды деятельности, которые относятся к категориям «Уход за детьми» и «Уход за пожилыми».

\section{3. Распределение затрат времени между потребителями временных трансфертов}

В первую очередь, согласно Методологии, необходимо рассчитать половозрастные профили затрат времени на ведение домашнего хозяйства. Для этого предлагается рассчитать среднее значение затраченного на домашнее производство времени в разрезе половозрастных групп.

Вторым шагом необходимо рассчитать половозрастные профили потребления времени, для этого нужно разделить все виды деятельности, выбранные ранее для анализа, на две группы: общие и направленные на определенные возрастные группы. К общим относится вся деятельность, бенефициарами которой выступают все члены домашнего хозяйства (уборка, готовка и прочее). Время, затраченное на такие виды деятельности, разделяется между всеми членами домохозяйства в равных долях, т.е. все потребляют равные части, в том числе и производитель данного блага. С видами деятельности, направленными на определенные возрастные группы, все немного сложнее, потребителями здесь выступают только представители соответствующих возрастных групп. Так, время, затраченное на уход за детьми, будет потреблено лишь членами домашнего хозяйства младше 18 лет.

После распределения производства и потребления домашнего продукта и услуг необходимо проверить, что отток (производство) трансфертов времени соответствует притоку (потреблению), т.е. в сумме все потоки дают ноль.

\section{4. Определение уровня рыночных заработных плат в соответствии с видами деятельности для получения рыночной оценки затрат времени}

Для определения рыночной стоимости единицы времени в рамках расчета трансфертов времени используется специализированная оценка, которая, как мы обсуждали ранее, предполагает использование данных по заработной плате соответствующих специалистов. 
Таким образом можно получить рыночную оценку стоимости выполнения каждой отдельной задачи по ведению домашнего хозяйства.

Согласно данной методике, используются данные по заработной плате до выплаты налогов, так как, если бы члены домохозяйства захотели отдать одну из своих задач на аутсорсинг, то цена, которую они в таком случае заплатили, была бы равна заработной плате наемного работника до выплаты налогов. Кроме того, согласно этой методике, для получения справедливой оценки домашнего труда необходимо скорректировать среднюю заработную плату на все выплаты и социальные отчисления, которые несет работодатель.

\section{Описание использованных данных ${ }^{4}$}

В данном исследовании использованы результаты Выборочного наблюдения использования суточного фонда времени населением (далее - Опрос), проведенного Федеральной службой государственной статистики Российской Федерации в период с 12 по 28 апреля 2014 г. [Выборочное наблюдение... 2015].

В Опросе принимало участие 10 тыс. домохозяйств, которые являются резидентами всех субъектов Российской Федерации. Согласно материалам Опроса, данные репрезентативны в целом по России, городским и сельским поселениям с различной численностью населения, по отдельным социально-демографическим группам населения.

Единицей наблюдения выступают лица в возрасте 12 лет и более, проживающие в частных домохозяйствах, отобранных для проведения Опроса. Опрос включает данные о затратах времени в следующих основных сферах деятельности: трудовая (оплачиваемая) деятельность, обучение в образовательных организациях, ведение собственного подсобного хозяйства, выполнение домашних обязанностей, уход за близкими, досуг.

При осуществлении Опроса использована модель многофазной выборки с реализацией на последней фазе двухступенчатого отбора. На каждой стадии формирования выборки применяли вероятностный отбор. В качестве основы для формирования выборки использован ежегодно актуализируемый информационный массив территориальной выборки многоцелевого назначения на базе информационного массива Всероссийской переписи населения 2010 г. Для распределения общего объема выборки (определяется в соответствии с теоретическими положениями выборочного метода) использована модель непропорционального размещения в рамках каждой из выделенных аналитических областей (городское и сельское население). Единицей отбора являлось жилое помещение (адрес домохозяйства). Единицами наблюдения были домохозяйства и члены домохозяйств в возрасте 12 лет и более.

Данные собирали посредством сочетания следующих методов:

- экспедиционный, при котором опрос и фиксирование ответов респондентов по программам вопросников наблюдения осуществлен специально обученными

\footnotetext{
${ }^{4}$ На основе информации Росстата о Выборочном наблюдении использования суточного фонда времени населением.
} 
работниками (интервьюерами) методом «лицом к лицу» по месту проживания респондентов в составе отобранного для наблюдения домохозяйства;

- саморегистрация респондентами информации о затратах времени на занятия различными видами деятельности в дневниках использования времени на протяжении 24 часов (от 4.00 утра дня наблюдения до 4.00 дня проведения опроса по индивидуальному вопроснику) с последующим сбором данных интервьюерами и кодированием полученной информации на основе классификатора видов деятельности для выборочного наблюдения использования суточного фонда времени населением.

При сборе данных использовали следующие инструменты:

- вопросник для домохозяйства;

- индивидуальный вопросник для лиц в возрасте 15 лет и более;

- дневник использования времени для лиц в возрасте 12-14 лет;

- дневник использования времени для лиц в возрасте 15 лет и более.

На каждом этапе проведения Опроса ответственные сотрудники проводили контрольные процедуры, направленные на обеспечение качества предоставляемых данных. В частности, при сборе Дневников интервьюер обязан был просмотреть их на предмет полноты записей, правильности регистрации затрат времени и четкости записей, что в дальнейшем необходимо для качественного их кодирования. На этапе формирования электронной базы данных ответственный сотрудник осуществлял 100\%-ю визуальную проверку правильности заполнения всех форм обследования, поступивших от интервьюеров. В случае обнаружения ошибок на этом этапе вносили изменения в бумажные носители на основе результатов запросов, адресованных интервьюеру. Во избежание ошибок, возникающих на этапе ввода данных, применяли специально разработанные программы контроля, позволяющие проверить соблюдение правил и логики заполнения форм обследования, содержащихся в соответствующих инструкциях, и провести дополнительный логический контроль данных. Ошибки, выявленные на этом этапе, исправляли также на основе поступающих от интервьюеров ответов на запросы.

Помимо контрольных процедур, приведённых выше, в рамках проведения Опроса на региональном уровне с непосредственным участием работников регионального и федерального уровней осуществляли следующие контрольные мероприятия:

- контрольные интервью, в ходе которых проводили сверку адресов фактически посещенных домохозяйств со списком адресов домохозяйств, направленных интервьюеру, а также соответствия зарегистрированных ответов респондентов и их фактических ответов, полученных при контрольном интервьюировании. Контрольные интервью проведены и по телефону (по ограниченному кругу вопросов);

- контрольные опросы, проведение интервьюером опросов и сбора информации по Дневникам использования времени в присутствии проверяющего лица. 


\section{РЕЗУЛЬТАТЫ ИССЛЕДОВАНИЯ}

\section{Оценка времени, расходуемого на выполнение работы по дому}

На основе данных Опроса были отобраны виды деятельности, которые, в первую очередь, соответствуют критерию третьей стороны, а также относятся к одной из следующих категорий:

1. уборка;

2. стирка белья (включая шитье, ремонт одежды);

3. кулинария (приготовление пищи и напитков);

4. обслуживание и ремонт;

5. уход за газонами и садами;

6. управление домохозяйством (включая финансы, планирование и др.);

7. уход за животными (не ветеринарный уход);

8. покупка товаров и услуг;

9. передвижения (связанные с деятельностью по уходу и закупкой товаров и услуг).

Из анализа было исключено время, затрачиваемое на уход за детьми и пожилыми людьми, так как эти виды деятельности будут подробнее рассмотрены в следующем разделе. Полный список видов деятельности приведен в Приложении.

Основываясь на Методологии [Donehower 2014], все затраты времени, относящиеся к анализируемым в данном разделе видам деятельности, были равномерно распределены между всеми членами домашнего хозяйства, включая индивида, затратившего время. Таким образом были получены объемы потребления каждого члена домашнего хозяйства. Просуммировав все произведенные (сколько времени индивид передал своим домочадцам в виде произведённых товаров и услуг) и потребленные (сколько времени индивид получил от домочадцев) трансферты времени, получили объемы производства и потребления трансфертов времени. Просуммировав объемы произведённых и потребленных трансфертов времени (временных трансфертов) в разрезе половозрастных групп, получили совокупные половозрастные профили распределения чистых трансфертов времени. Под чистыми трансфертами времени (временными трансфертами) в данном случае понимается разница между потребленными и произведенными индивидом трансфертами времени. Усреднив объемы производства и потребления трансфертов времени в рамках половозрастных групп, получили их удельные половозрастные профили (рисунок 2).

Как можно видеть на рисунке 2, начиная с 20 и вплоть до 80 лет женщины совокупно производят трансфертов времени больше, чем потребляют, таким образом обеспечивая потребности в домашних услугах не только детей и пожилых, но и мужчин. Также следует отметить наличие двух пиков в женском профиле распределения трансфертов времени. Первый пик приходится на женщин в возрасте от 24 до 36 лет, что соответствует времени рождения детей и при прочих равных приводит к росту объема домашних обязанностей, ложащихся на плечи молодых мам. Второй пик соответствует женщинам в возрасте от 53 до 60 лет, что объясняется выходом на пенсию, и, как следствие, увеличением объема свободного времени, которое женщины расходуют в том числе и на выполнение обязанностей по дому. Чистыми потребителями трансфертов времени женщины становятся 
лишь на заключительном этапе жизни (после 80 лет), что соответствует результатам некоторых зарубежных исследований [Anxo et al. 2007].

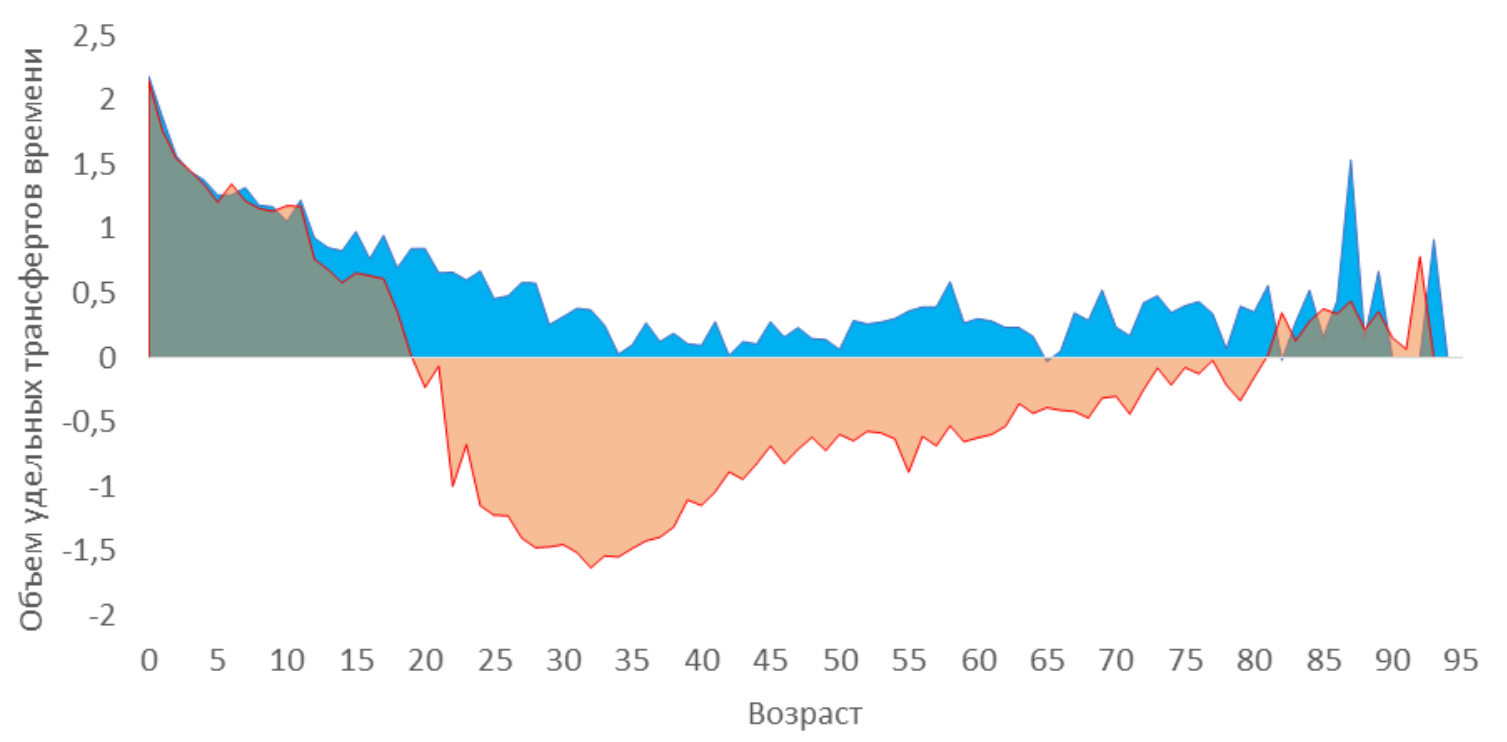

口 Удельные трансферты времени (мужчины) $\square$ Удельные трансферты времени (женщины)

\section{Рисунок 2. Удельные половозрастные профили распределения чистых трансфертов времени, расходуемого на выполнение работы по дому, часы за сутки на одного представителя половозрастной группы}

Источник: Рассчитано и составлено авторами на основе данных [Выборочное наблюдение... 2015].

Мужчины на протяжении практически всей жизни остаются потребителями трансфертов времени. Как видно на рисунке 2, хотя удельные временные трансферты мужчин практически никогда не спускаются в отрицательную область (область производства трансфертов времени), мужчины в зрелом возрасте после 33 лет заметно увеличивают производство трансфертов времени, приближаясь к своему уровню потребления, что на графике приближает их к нулевому значению. Растущее вовлечение мужчин в производство домашних благ и услуг может объясняться наступлением определенных жизненных этапов: вступление в брак, рождение детей/внуков и первые годы их жизни, старение родителей, выход на пенсию и др. Кроме того, следует обратить внимание на более раннее по сравнению с женщинами наступление пиков потребления трансфертов времени в самых старших возрастах (это может быть следствием меньшей продолжительности жизни мужчин по сравнению с женщинами, статистические погрешности малочисленных совокупностей наступают в более ранних возрастах). Разница между временными трансфертами, производимыми женщинами и мужчинами одного возраста, может достигать двух часов в сутки, что говорит о том, что женщины в день на домашнюю работу расходуют почти на 2 часа больше мужчин.

В таблице 1 представлена матрица частостей распределения трансфертов времени, отражающая долю (процент) от случаев потребления представителями определенной половозрастной группы потребителей трансфертов времени (столбцы) трансфертов времени, произведенных представителями той или иной половозрастной группы (строки). 
К примеру, в ячейке 1:1 значение $14,8 \%$ означает, что в $14,8 \%$ случаев трансферты, произведенные мужчинами в возрасте от 0 до 19 лет, были потреблены представителями той же половозрастной группы (их домочадцами мужского пола в возрасте от 0 до 19 лет). Заливка ячеек таблицы 1 отражает относительную величину показателей: от красной заливки для минимального значения (в нашем случае 0,00\%) до зеленой заливки для максимального значения (48,8\%).

\section{Таблица 1. Матрица частостей распределения трансфертов времени от} производителей потребителям временных трансфертов, \%

\begin{tabular}{|c|c|c|c|c|c|c|c|c|c|c|c|}
\hline & \multirow[b]{2}{*}{ Возраст } & \multicolumn{5}{|c|}{ Потребители (мужчины) } & \multicolumn{5}{|c|}{ Потребители (женщины) } \\
\hline & & $0-19$ & $20-39$ & $40-59$ & $60-79$ & $80+$ & $0-19$ & $20-39$ & $40-59$ & $60-79$ & $80+$ \\
\hline \multirow{5}{*}{ 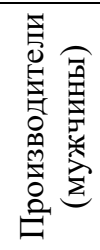 } & $0-19$ & 14,8 & 11,4 & 18,6 & 1,1 & 0,2 & 13,5 & 19,4 & 17,6 & 2,6 & 0,7 \\
\hline & 20-39 & 23,3 & 2,4 & 4,4 & 1,9 & 0,1 & 21,9 & 32,3 & 10,0 & 3,3 & 0,3 \\
\hline & $40-59$ & 15,7 & 8,6 & 0,4 & 0,8 & 0,3 & 14,5 & 13,5 & 39,8 & 5,0 & 1,4 \\
\hline & $60-79$ & 5,8 & 8,5 & 3,2 & 0,0 & 0,0 & 4,9 & 8,6 & 18,9 & 48,8 & 1,3 \\
\hline & $80+$ & 2,5 & 3,8 & 11,3 & 1,3 & 0,0 & 3,8 & 5,0 & 13,8 & 33,8 & 25,0 \\
\hline \multirow{5}{*}{ 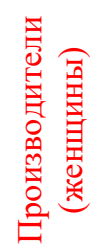 } & 0-19 & 15,7 & 12,8 & 16,0 & 1,6 & 0,1 & 12,4 & 20,8 & 16,8 & 3,4 & 0,5 \\
\hline & $20-39$ & 26,8 & 25,5 & 8,3 & 1,8 & 0,1 & 25,4 & 1,8 & 6,8 & 3,3 & 0,2 \\
\hline & $40-59$ & 15,1 & 14,4 & 34,4 & 5,8 & 0,4 & 13,9 & 11,0 & 0,5 & 3,1 & 1,5 \\
\hline & $60-79$ & 8,5 & 10,1 & 11,8 & 37,6 & 2,1 & 8,2 & 12,1 & 7,1 & 0,5 & 1,9 \\
\hline & $80+$ & 7,9 & 7,3 & 20,3 & 6,2 & 14,1 & 4,5 & 7,9 & 21,5 & 9,6 & 0,6 \\
\hline
\end{tabular}

Источник: Рассчитано и составлено авторами на основе данных [Выборочное наблюдение... 2015].

Как видим, чаще всего потребителями домашних услуг и продуктов выступают дети, причем предоставляют им данные услуги женщины и мужчины в возрасте от 20 до 39 лет, которые вероятнее всего являются их родителями или опекунами, а также провайдерами трансфертов времени для возрастной группы от 0 до 19 лет выступают женщины и мужчины в возрасте от 40 до 59 лет, которые, вероятно, приходятся им бабушками и дедушками. Следует отметить, что трансферты времени часто распределяются между супругами: высокие значения показателей на диагоналях правого верхнего и левого нижнего квадрантов. Кроме того, из таблицы 1 видно, что женщины старше 60 лет чаще получают помощь в ведении хозяйства в сравнении со своими ровесниками мужского пола, однако также важно отметить тот факт, что женщины в возрасте $80+$, несмотря на свой преклонный возраст, часто являются провайдерами домашних услуг для своих детей: мужчин и женщин в возрасте 40-59 лет.

Данные таблицы 2 отражают размер трансфертов времени (в часах за сутки), потребленных представителями определённой половозрастной группы (столбцы) и произведенных представителями той или иной половозрастной группы (строки). К примеру, в ячейке 1:1 значение 0,13 означает, что 0,13 часа за сутки трансфертов времени было произведено мужчинами в возрасте от 0 до 19 лет и потреблено представителями той же половозрастной группы (их домочадцами мужского пола в возрасте от 0 до 19 лет). Заливка ячеек таблицы 2 отражает относительную величину показателей: от красной заливки для минимального значения (в нашем случае $0,11 \%$ ) до зеленой заливки для максимального значения $(1,89 \%)$. 
Таблица 2. Матрица распределения потоков трансфертов времени от производителей потребителям временных трансфертов, часы

\begin{tabular}{|c|c|c|c|c|c|c|c|c|c|c|c|}
\hline \multirow{2}{*}{\multicolumn{2}{|c|}{ Возраст }} & \multicolumn{5}{|c|}{ Потребители (мужчины) } & \multicolumn{5}{|c|}{ Потребители (женщины) } \\
\hline & & $0-19$ & $20-39$ & $40-59$ & $60-79$ & $80+$ & $0-19$ & $20-39$ & $40-59$ & $60-79$ & $80+$ \\
\hline \multirow{5}{*}{ 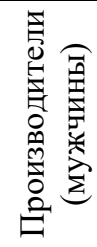 } & $0-19$ & 0,13 & 0,16 & 0,17 & 0,13 & 0,31 & 0,16 & 0,17 & 0,17 & 0,21 & 0,11 \\
\hline & $20-39$ & 0,36 & 0,38 & 0,33 & 0,34 & 0,23 & 0,37 & 0,39 & 0,39 & 0,37 & 0,27 \\
\hline & $40-59$ & 0,42 & 0,47 & 0,74 & 0,49 & 0,57 & 0,44 & 0,46 & 0,59 & 0,60 & 0,80 \\
\hline & $60-79$ & 0,48 & 0,54 & 0,61 & НД & НД & 0,50 & 0,51 & 0,73 & 0,84 & 0,71 \\
\hline & $80+$ & 0,54 & 1,41 & 0,49 & 0,29 & НД & 0,21 & 0,19 & 0,46 & 0,76 & 0,82 \\
\hline \multirow{5}{*}{ 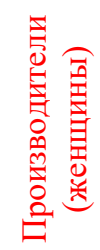 } & $0-19$ & 0,23 & 0,28 & 0,25 & 0,25 & 0,26 & 0,24 & 0,21 & 0,25 & 0,17 & 0,26 \\
\hline & $20-39$ & 0,94 & 0,91 & 0,73 & 0,60 & 0,71 & 0,93 & 0,49 & 0,57 & 0,62 & 0,60 \\
\hline & $40-59$ & 0,77 & 0,78 & 0,90 & 0,92 & 1,08 & 0,74 & 0,69 & 0,54 & 0,66 & 0,86 \\
\hline & $60-79$ & 0,69 & 0,84 & 1,02 & 1,13 & 1,18 & 0,62 & 0,71 & 0,72 & 0,75 & 1,30 \\
\hline & $80+$ & 0,36 & 0,55 & 0,75 & 1,05 & 0,98 & 0,49 & 0,43 & 0,52 & 0,69 & 1,89 \\
\hline
\end{tabular}

Источник: Рассчитано и составлено авторами на основе данных [Выборочное наблюдение... 2015].

Примечание: НД-нет данных.

Учет объемов передаваемых трансфертов меняет общую картину. В частности, если с точки зрения показателей таблицы 1 (частостей), профили распределения трансфертов времени, производимых мужчинами и женщинами, практически идентичны, то с точки зрения абсолютных показателей, представленных в таблице 2, очевидно, что основным источником временных трансфертов в контексте работы по дому являются женщины. В среднем, каждая женщина независимо от возраста передает за день около часа временных трансфертов своему ровеснику мужского пола (диагональ левого нижнего квадранта) и еще почти час старшим членам домашнего хозяйства: мужчинам и женщинам в возрасте 80+. Еще одной группой потребителей трансфертов времени, расходуемого на ведение домашнего хозяйства, являются дети (возрастная группа 0-19 лет), которым женщины в возрасте от 20 до 39 лет передают почти час в день. Также важно отметить роль старшего поколения женщин в помощи в ведении домашнего хозяйства. Так, женщины в возрасте от 40 до 79 лет передают своим детям (возрастная группа 20-39 лет) и внукам (возрастная группа 0-19 лет) около 0,75 часа или 45 минут в день.

Что качается домашнего труда мужчин, то из таблицы 2 видно, что с возрастом мужчины все больше времени уделяют домашнему хозяйству. Основными потребителями трансфертов времени, произведенных мужчинами, выступают их ровесницы женского пола и пожилые члены домашнего хозяйства.

\section{Оценка времени, расходуемого на заботу о близких}

Забота о близких составляет значительную часть жизни каждого из нас: время, проведенное с ребенком, или время, затраченное на помощь пожилым родственникам, играет огромную роль не только для нас, но и для дорогих нам людей. Известно, что семья является самым ранним агентом социализации ребенка, стиль воспитания сильно влияет на развитие у детей навыков выстраивания отношений и на успехи в школе. В частности, анализ данных Британского когортного исследования (BCS) [Layard et al. 2014] показал, что уровень удовлетворенности жизнью людей в возрасте 34 лет в значительной степени обусловлен 
когнитивными и некогнитивными навыками, развитыми в детстве.

Кроме того, крайне важно признать экономическую ценность неформального ухода за пожилыми людьми, поскольку такие формы семейных обязательств быстро становятся все более распространенными среди взрослых трудоспособного возраста, особенно женщин [Bianchi 2011]. Следует отметить тот факт, что получение образования, продвижение в рабочем статусе и карьере могут быть отложены, если ожидается, что взрослые дети будут обеспечивать уход за пожилыми родителями, которые находятся в плохом физическом или психическом состоянии [Choi 2011]. В контексте оказания неоплачиваемых услуг пожилым членам домашнего хозяйства важно упомянуть о том, что пожилые люди, получая временные трансферты, зачастую выступают одним из источников финансовых ресурсов для своих детей и внуков. В частности, в ряде европейских исследований было подтверждено, что взрослые дети в основном получают финансовые трансферты от своих родителей, тогда как в свою очередь дети поддерживают своих родителей посредством трансфертов времени [Szydlik 2004, Attias-Donfut 2000]. В работе Леопольда [Leopold, Raab 2010] было показано, что такой обмен времени и денег имеет место не только в долгосрочной перспективе (дети помогают родителям, понимая, что они в разные периоды своей жизни уже получили или еще могут получить финансовую помощь от родителей), но и в краткосрочной. На основе данных Европейского опроса здоровья, старения и выхода на пенсию (SHARE), было также доказано и обратное: дети, ухаживающие за родителями, получали большую финансовую поддержку по сравнению с их сестрами и братьями, уделявшими родителям меньше времени. Однако подобный комплексный межпоколенческий обмен материальными и временными ресурсами выходит за рамки данного исследования.

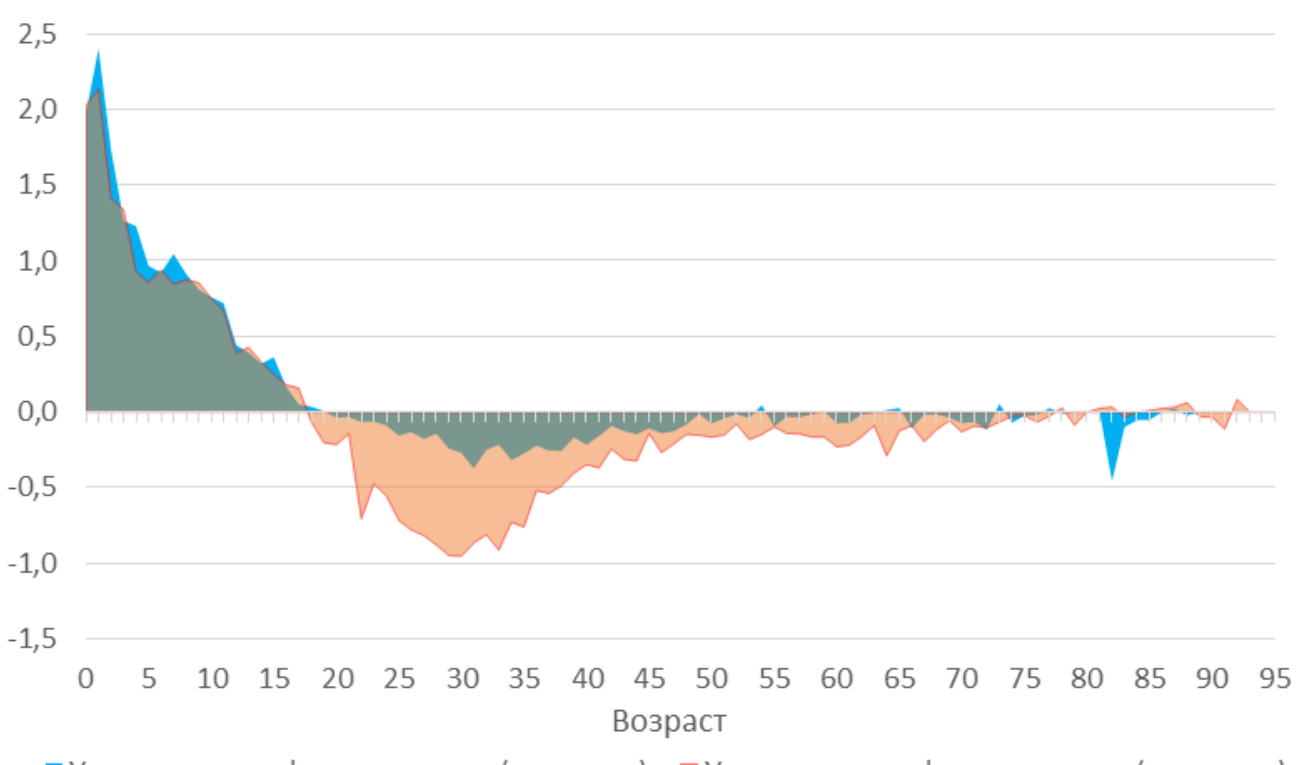

चдельные трансферты времени (мужчины) $\square$ Удельные трансферты времени (женщины)

Рисунок 3. Удельные половозрастные профили распределения чистых трансфертов времени, расходуемого на заботу о близких, часы за сутки на одного представителя половозрастной группы

Источник: Рассчитано и составлено авторами на основе данных [Выборочное наблюдение... 2015]. 
На основе данных Опроса были рассчитаны профили распределения удельных трансфертов времени в разрезе пола и возраста (рисунок 3). Первое, на что хотелось бы обратить внимание, это разница в объеме трансфертов, произведенных в рамках экономики заботы и ведения домашнего хозяйства. На наш взгляд, почти двукратный разрыв в значениях связан со спецификой исследуемой деятельности. Забота о детях или пожилых, как правило, выделяется как отдельное действие наряду с основным - выполнением обязанностей по дому, что может повлиять на распределение часов в дневнике респондента. При этом продукт выполнения обязанностей по дому распределяется между всеми членами домохозяйства, в том числе детьми и пожилыми.

Как мы видим на рисунке 3, женщины гораздо более склонны посвящать свое время заботе о близких по сравнению с мужчинами. Женщины в день на заботу о близких могут тратить почти на час больше своих ровесников мужского пола. Как и в случае трансфертов, производимых при выполнении работы по дому, для женского профиля характерно наличие пика в возрасте 24-36 лет. Увеличение нагрузки на женщин в возрасте 24-36 лет, на наш взгляд, связано с рождением детей, первыми годами их жизни, старением старших родственников (родителей, бабушек/дедушек) и, как следствие, возникновением необходимости физического ухода за пожилыми людьми. Пик производства женщинами трансфертов в рамках экономики заботы совпадает с наступлением пика в производстве временных трансфертов при ведении домашнего хозяйства, что говорит о наличии повышенной нагрузки на женщин трудоспособного возраста.

Разрыв во времени, уделяемом уходу за близкими людьми, между мужчинами и женщинами, который мы получили в результате наших расчетов, является распространенным явлением. Многие исследователи наблюдали, что именно женщины большую часть времени занимаются организацией неформального ухода. Данные Висконсинского исследования [Bianchi 2011] показывают, что американские женщины предоставляют гораздо больше часов неоплачиваемой помощи пожилым и детям, чем мужчины. Это оказывает значительное давление на решение о занятости женщин и может снизить качество их жизни и повлиять на решение о вступлении в брак [Riley, Bowen 2005]. По данным [Anxo et al. 2007], в США гендерный разрыв во времени, уделяемом уходу за детьми, постоянно расширяется. Из-за высокой стоимости формального ухода за детьми матери чаще, чем отцы или другие члены семьи, вынуждены отказываться от оплачиваемой работы в пользу ведения домашнего хозяйства и ухода за близкими. По мнению одних исследователей [Brandt, Haberkern, Szydlik 2009], данное явление объясняется специфической для женщин склонностью к заботе о других членах семьи. По мнению других [Темкина, Роткирх 2002], такое распределение времени - результат гендерного контракта женщин и мужчин с государством, сложившегося на базе патриархального общественного устройства, существовавшего достаточно длительный исторический период.

\section{Экономическая оценка трансфертов времени}

В этом разделе приведены результаты экономической оценки произведенных трансфертов времени, полученной косвенным методом. С использованием удельных половозрастных профилей производства и данных Росстата о численности населения в разрезе 
половозрастных групп были построены совокупные профили производства трансфертов времени для всего населения России за 2014 г. На основе полученных профилей с использованием различных оценок стоимости времени были рассчитаны оценки неоплачиваемого труда россиян на 2014 г. (таблица 3).

Таблица 3. Экономическая оценка трансфертов времени, произведенных в рамках экономики заботы и ведения домашнего хозяйства

\begin{tabular}{|c|c|c|c|c|c|c|c|c|}
\hline & \multicolumn{2}{|c|}{ Оценка 1} & \multicolumn{2}{|c|}{ Оценка 2} & \multicolumn{2}{|c|}{ Оценка 3} & \multicolumn{2}{|c|}{ Оценка 4} \\
\hline & $\begin{array}{c}\text { сумма, } \\
\text { трлн руб. }\end{array}$ & $\begin{array}{l}\text { доля от } \\
\text { ВВП, \% }\end{array}$ & $\begin{array}{c}\text { сумма, } \\
\text { трлн руб }\end{array}$ & $\begin{array}{l}\text { доля от } \\
\text { ВВП, \% }\end{array}$ & $\begin{array}{l}\text { сумма, } \\
\text { трлн руб. }\end{array}$ & $\begin{array}{l}\text { доля от } \\
\text { ВВП, \% }\end{array}$ & $\begin{array}{c}\text { сумма, } \\
\text { трлн руб. }\end{array}$ & $\begin{array}{l}\text { доля от } \\
\text { ВВП, \% }\end{array}$ \\
\hline $\begin{array}{l}\text { Ведение } \\
\text { домашнего } \\
\text { хозяйства }\end{array}$ & 16,6 & 21,0 & 16,3 & 20,6 & 3,1 & 3,9 & 15,5 & 19,6 \\
\hline $\begin{array}{l}\text { Экономика } \\
\text { заботы }\end{array}$ & 3,4 & 4,3 & 3,3 & 4,2 & 0,6 & 0,8 & 3,1 & 3,9 \\
\hline ИТОГО & 20,0 & 25,3 & 19,7 & 24,8 & 3,7 & 4,7 & 18,6 & 23,5 \\
\hline
\end{tabular}

Источник: Рассчитано и составлено авторами на основе данных [Выборочное наблюдение... 2015].

Первая и вторая оценки стоимости трансфертов времени в таблице 3 представляют альтернативную стоимость времени, затраченного на ведение домашнего хозяйства и уход за близкими людьми. В качестве стоимости единицы времени были использованы статистические данные с сайта Росстата ${ }^{5}$ по средней заработной плате в разрезе возрастных групп (оценка 1), а также по средней заработной плате по уровню образования (оценка 2). Данные о возрасте и уровне образования каждого индивида, вошедшего в выборку, содержатся в материалах Опроса. Зная среднюю стоимость единицы времени индивида в зависимости от его возраста или уровня образования, а также объем трансфертов времени, который он(а) произвел(а) в рамках ведения домашнего хозяйства и экономики заботы, мы смогли рассчитать стоимость произведённых трансфертов времени. Время, расходуемое на производство трансфертов времени, было рассчитано на основе данных Опроса и для оценки экономического эффекта экстраполировано на все население России за 2014 г. Таким образом, альтернативная стоимость времени составила от 19,7 до 20,0 трлн руб., что соответствует примерно 24,8-25,3\% ВВП за 2014 г.

При расчете универсальной оценки 3 мы использовали показатель МРОТ (минимальный размер оплаты труда), который в 2014 г. составил 5554 руб. в месяц. При использовании показателя МРОТ в качестве цены времени, расходуемого на ведение домашнего хозяйства, универсальная оценка стоимости времени составила 3,7 трлн руб., что соответствует примерно 4,7\% ВВП за 2014 г.

Для расчета специализированной оценки 4 использованы статистические данные с сайта Росстата по заработной плате по видам экономической деятельности. Специализированная оценка времени, расходуемого на ведение домашнего хозяйства и заботу о детях и пожилых, составила 18,6 трлн руб., что соответствует примерно 23,5\% ВВП за 2014 г.

\footnotetext{
${ }^{5}$ URL: http://www.gks.ru/wps/wcm/connect/rosstat_main/rosstat/ru/statistics/accounts/
} (дата обращения: 19.11.2018). 
Выбор оценки стоимости единицы времени, как мы видим из таблицы 3 , во многом определяет результат оценки произведенных трансфертов времени. Использование в данном исследовании нескольких разных оценок неоплачиваемого труда домашних хозяйств: от МРОТ до оценок, учитывающих индивидуальные характеристики индивида (возраст, уровень образования) или виды осуществляемой деятельности, - позволяет показать, что даже если оценивать эту «скрытую» для рыночной экономики деятельность индивидов по минимальной стоимости (МРОТ), все равно она составляет довольно значительную часть ВВП России. На наш взгляд, более справедливая оценка производимых трансфертов времени составляет от 23,5 до 25,3\% от ВВП России за 2014 г.

Данная оценка сопоставима с аналогичными показателями для других стран, в частности, доля неоплачиваемого труда в США составила 20\% от ВВП за 2004 г. [Landefeld, Fraumeni, Vojtech 2009], для европейских стран данный показатель колеблется от 24\% в Латвии до 57\% в Германии [Giannelli, Mangiavacchi, Piccoli 2011]. Кроме того, если сравнить полученные результаты с данными советского периода [Социология в России 1996], по которым в период 1922-1934 гг. время, расходуемое на домашний труд, составляло 12 часов в неделю для мужчин и 36,5 часа для женщин, то по нашим оценкам аналогичные показатели за 2014 г. составляют около 10,5 часа для мужчин и 24,5 часа для женщин трудоспособного возраста. Данное сравнение, учитывая разницу методик сбора данных, не совсем корректно, однако позволяет увидеть общие тенденции. В частности, сокращение объемов неоплачиваемого труда мужчин и женщин может объясняться использованием трудосберегающих технологий в домохозяйстве и развитием сектора услуг в экономике; более существенное сокращение неоплачиваемого труда женщин по сравнению с мужчинами может быть связано с изменением гендерных ролей внутри семьи и перераспределением времени на домашнюю работу. Возможно, мужчины стали тратить больше времени на домашнюю работу не только во второй половине жизни, но и по выходным дням [Калабихина 2004; Итоги... 2010]. Однако все эти вопросы требуют более детальной проработки и анализа, в первую очередь, по причине различий в методологии сбора информации о бюджетах времени.

\section{ЗАКЛЮЧЕНИЕ}

Анализ данных Выборочного наблюдения использования суточного фонда времени населением Российской Федерации позволил понять, что производство благ и услуг внутри домашних хозяйств является значимой частью экономики страны, составляя по разным оценкам от 3,9 до 21,0\% годового ВВП. Экономика заботы также играет значительную роль, составляя от 0,8 до 4,3\% от ВВП России за 2014 г. или в среднем около 0,5 часа в день. Таким образом, оценка «невидимого» для рыночной экономики продукта составляет до 20,0 трлн руб. или 25,3\% ВВП за 2014 г. Такая оценка сопоставима с данными исследований в развитых странах.

Традиционные выводы о большем вкладе женщин как в экономику заботы, так и в ведение домашнего хозяйства подкреплены оригинальными выводами о наличии возрастных пиков у мужчин и женщин в производстве и потреблении трансфертов времени и о межпоколенческих и межгендерных трансфертах. 
Матрица производителей и потребителей времени в домашнем хозяйстве (времени на ведение домашнего хозяйства) позволила сделать следующие выводы. В среднем каждая женщина независимо от возраста передает за день около часа временных трансфертов своему ровеснику мужского пола и еще почти час старшим членам домашнего хозяйства: мужчинам и женщинам в возрасте $80+$. Еще одной группой потребителей трансфертов времени, расходуемого на ведение домашнего хозяйства, являются дети (возрастная группа 0-19 лет), которым женщины в возрасте от 20 до 39 лет передают почти час трансфертов времени в день. Также важно отметить роль старшего поколения женщин в помощи в ведении домашнего хозяйства: женщины в возрасте от 40 до 79 лет передают своим детям (возрастная группа 20-39 лет) и внукам (возрастная группа 0-19 лет) около 0,75 часа или 45 минут в день.

Что касается домашнего труда мужчин, то с возрастом мужчины все больше времени уделяют домашнему хозяйству. Основными потребителями трансфертов времени, произведенных мужчинами, выступают их ровесницы женского пола и пожилые члены домашнего хозяйства.

Принимая во внимание тот факт, что, согласно Постановлению Правительства РФ от 27 ноября 2010 г. №946 "Об организации в Российской Федерации системы федеральных статистических наблюдений по социально-демографическим проблемам и мониторинга экономических потерь от смертности, заболеваемости и инвалидизации населения", опросы использования суточного фонда времени населением с 2019 г. будут проводиться 1 раз в 5 лет и будут охватывать уже 45 тыс. домашних хозяйств, данное исследование имеет также и некоторую методологическую ценность. В частности, наши результаты могут быть использованы при составлении временных рядов при анализе тенденции и эффективности проводимых мер социально-демографической политики. Показатели Национальных счетов трансфертов времени являются удобным инструментом анализа потенциальных последствий демографических процессов. Профили производства и потребления трансфертов времени, рассчитанные в рамках Национальных счетов трансфертов времени, дают возможность выявить группы населения, испытывающие дефицит ресурсов, а также группы населения, обеспечивающие собственное потребление и выступающие донорами времени для других членов домохозяйства. Национальные счета трансфертов времени позволяют наглядно представить возможные последствия принятия тех или иных решений в области социально-демографической политики и тем самым дают возможность оперативно реагировать на изменение структуры и потребностей населения.

В будущих исследованиях мы планируем рассмотреть детерминанты распределения бюджетов времени в домохозяйствах по данным 2014 г., а также проследить, как меняется распределение времени в домашнем хозяйстве и факторы, определяющие это распределение, по данным 2019 г. Один из интересующих нас частных вопросов: в какой степени снижение участия женщин в домашнем труде связано с ростом использования трудосберегающих технологий, а в какой степени - с ростом эгалитарности в семейных отношениях, т.е. замещением женского домашнего труда мужским. Второй вопрос связан с отсутствием пиков у женщин и мужчин в старших возрастах в производстве трансфертов времени в рамках экономики заботы. Возможно, в домохозяйствах с маленькими детьми помощь старшего поколения в уходе за внуками и внучками осуществляется посредством 
увеличения затрат времени на ведение домохозяйства, а не напрямую увеличением экономики заботы. Отдельное направление исследования - междомохозяйственные трансферты времени (в рамках расширенной семьи, члены которой проживают в разных домохозяйствах).

\section{ЛИТЕРАТУРА}

Выборочное наблюдение использования суточного фонда времени населением Российской Федерации (2015). Федеральная служба государственной статистики (Росстат). URL: http://www.gks.ru/free_doc/new_site/population/urov/sut_fond/survey0/index.html (дата обращения: 12.03.2018).

Гвоздева Г.П. (2000). Неоплачиваемый труд как фактор адаптации россиян в период кризиса // Вестник НГУ. Серия: Социально-экономические науки. 1. 1: 55-68.

Итоги пилотного выборочного обследования использования (бюджета) времени населением (2010). М.: ФСГС: 7-78.

Калабихина И.Е. (2004). Время на домашнюю работу: факторы нагрузки // Материалы научной конференции «Ломоносовские чтения 2004-2006 гг.». М.: ТЕИС

Калабихина И.Е. (2011). Гендерный переход и качество жизни // Уровень жизни населения регионов России. 8: 42-48.

Патрушев В.Д., В.А. Артемов, О.В. Новохацкая (2001). Изучение бюджетов времени в России ХХ в. // Социологические исследования. 6: 112-120.

Пруденский Г.А. (1972). Проблемы рабочего и внерабочего времени. М.: Наука. 335 с.

Социология в России (1996). Учебник / Под ред. В.А. Ядова. М.: Издательство «На Воробьевых». 700 с.

Струмилин С. Г. (1957). Проблемы экономики труда. М.: Госполитиздат. 735 с.

Темкина А.А., А. Роткирх (2002). Советские гендерные контракты и их трансформация в современной России // Социологические исследования. 11: 4-14.

Albertini M., M. Kohli, C. Vogel (2007). Intergenerational transfers of time and money in European families: common patterns - different regimes? // Journal of European Social Policy. 17: 319-334.

Anxo D., L. Flood, L. Mencarini, A. Pailhé, A. Solaz, M.L. Tanturri (2007). Time allocation between work and family over the life-cycle: A comparative gender analysis of Italy, France, Sweden and the United States // IZA DP. 3193: 1-35.

Apps P., R. Rees (2005). Gender, time use and public policies over the life-cycle // IZA. 1855: 136.

Attias-Donfut C., F.-C. Wolff (2000). Complementarity between private and public transfers // The Myth of Generational Conflict / S. Arber, C. Attias-Donfut, eds. London: Routledge: 47 68.

Becker G.S. (1965). A theory of the allocation of time // The Economic Journal. 75(299): 493517.

Bianchi S.M. (2011). Family change and time allocation in American families // The Annals of the American Academy of Political and Social Science. 638: 21-44. 
Brandt M., K. Haberkern, M. Szydlik (2009). Intergenerational help and care in Europe // European Sociological Review. 25(5): 585-601.

Choi H. (2011). Parents' health and adult children's subsequent working status: A perspective of intergenerational transfer and time allocation // Journal of Family and Economic Issues. 32(3): 493-507.

Clark C. (1958). The economics of housework // Bulletin of the Oxford institute of Statistics: 205-211.

Deloach S.B., A.L. Hoffman (2002). Russia's second shift: is housework hurting women's wages? // Atlantic Economic Journal. 30(4): 422-32.

Donehower G. (2014). Incorporating gender and time use into NTA: Estimating NTA and national time transfer accounts by sex. URL:

http://www.ntaccounts.org/web/nta/show/Gender,\%20Time\%20use (дата обращения: 12.03.2018).

Dukhovnov D., E. Zagheni (2015). Who takes care of whom in the United States? Time transfers by age and sex // Population and Development Review 41(2): 183-206.

Fitzgerald J. (1990). Measuring the value of household output: a comparison of direct and indirect approaches // Review of Income and Wealth. Series 36. 2: 129-141.

Giannelli G., L. Mangiavacchi, L. Piccoli (2011). GDP and the value of family caretaking: How much does Europe care? // Applied Economics. 44(16): 2111- 2131.

Hamdad M. (2003). Valuing households' unpaid work in Canada, 1992 and 1998: Trends and sources of change // Statistics Canada Economic Conference: 1-14.

Hochschild A. (1989). The Second Shift. Working Parents and the Revolution at Home // New York: Viking. 322 p.

Human Development Report (2006). Beyond scarcity: Power, poverty and the global water crisis. United Nations Development Programme (UNDP). URL: http://hdr.undp.org/sites/default/files/reports/267/hdr06-complete.pdf (accessed: 29.09.2018).

ICATUS (2016). United Nations Statistics Division. International Classification of Activities for Time Use Statistics 2016.

Kuznets S., L. Epstein, E. Jenks (1944). National Income and its Composition // National Bureau of Economic Research. 388 p.

Landefeld J.S., B.M. Fraumeni, C.M. Vojtech (2009). Accounting for household production: A prototype satellite account using the American time use survey // Review of Income and Wealth. Series 55(2): 205-225.

Layard R., A. Clark, F. Cornaglia, N. Powdthavee, J. Vernoit (2014). What predicts a successful life? A life-course model of wellbeing // Economic Journal. 124: 720-738.

Leopold T., M. Raab (2010). Intergenerational exchange of time and money: Short-term reciprocity in parent-child relationships // National Council on Family Relations: 105-119.

Lewis J. (1992). Gender and the development of welfare regimes // Journal of European Social Policy. 2(3): 159-173.

Löfmark M.H. (2007). Gender and time allocation differences in Taganrog, Russia // International Journal of Time Use Research. 4. 1: 69-92.

McDonald P. (2000). Gender equity in theories of fertility transition // Population and Development Review. 26(3): 427-439. 
Mitchell W., W.I. King, F.R. Macaulay, C.W. Knauth (1921). Income in the United States: its Amount and Distribution // National Bureau of Economic Research. 154 p.

Reid M. (1934). Economics of Household Production // New York: Wiley. 424 p.

Riley L.D., C.P. Bowen (2005). The sandwich generation: Challenges and coping strategies of multigenerational families // The Family Journal. 13(1): 52-58.

Szydlik M. (2004). Inheritance and inequality: theoretical reasoning and empirical evidence // European Sociological Review. 20: 31-45.

Vargha L., R.I. Gál, M.O. Crosby-Nagy (2017). Household production and consumption over the life cycle: National time transfer accounts in 14 European countries // Demographic Research. 36(32): 905-944. URL:https://www.demographicresearch.org/volumes/vol36/32/36-32.pdf (дата обращения: 29.09.2018).

Webber D. (2017). Measuring and valuing unpaid household service work // Workshop on Gender Statistics (Belgrade, Serbia, 27-28 November): 1-35. 


\section{ПРИЛОЖЕНИЕ}

Список видов деятельности, вошедших в анализ

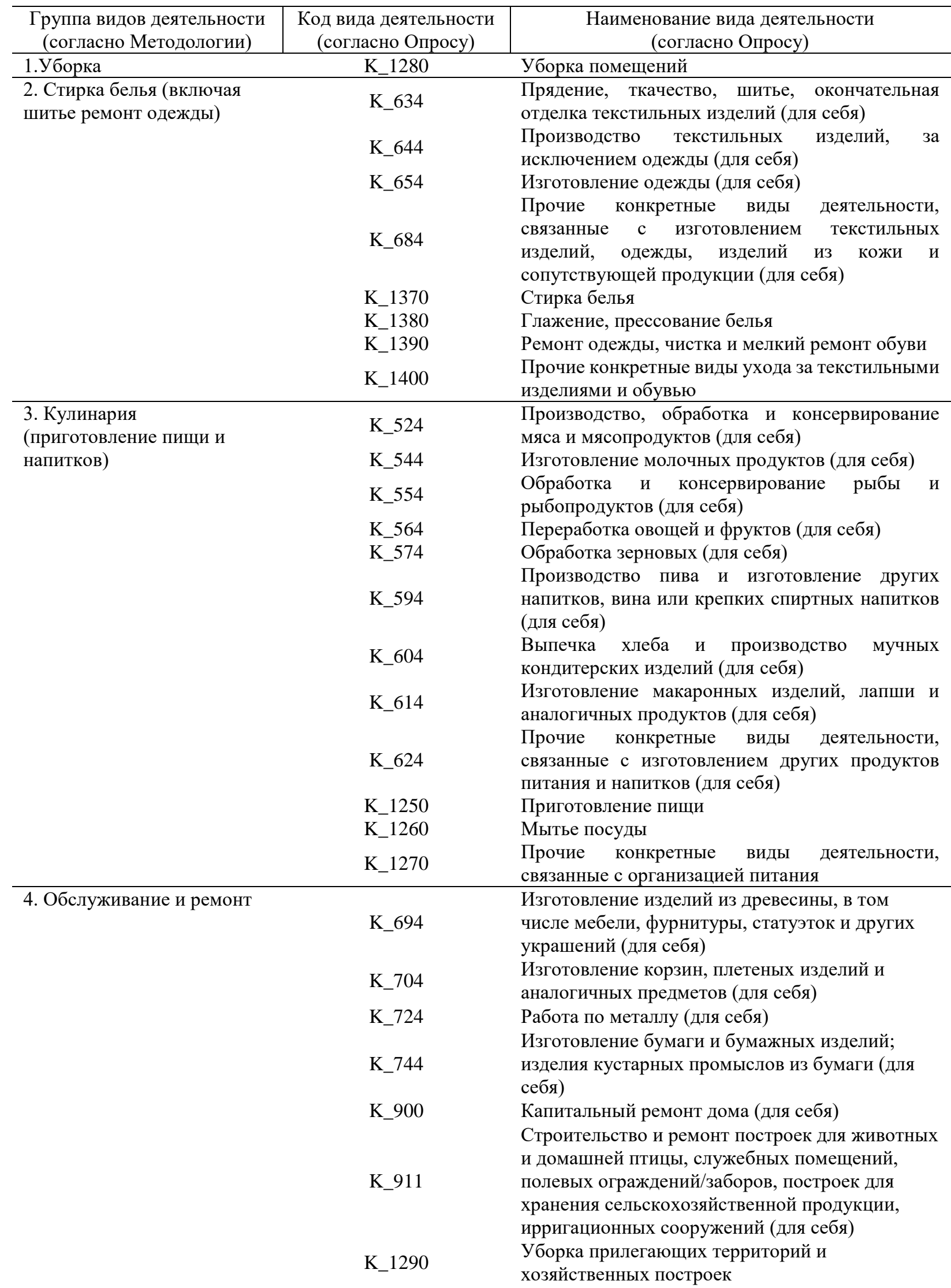




\begin{tabular}{|c|c|c|}
\hline $\begin{array}{l}\text { Группа видов деятельности } \\
\text { (согласно Методологии) }\end{array}$ & $\begin{array}{l}\text { Код вида деятельности } \\
\text { (согласно Опросу) }\end{array}$ & $\begin{array}{l}\text { Наименование вида деятельности } \\
\text { (согласно Опросу) }\end{array}$ \\
\hline & K_1310 & $\begin{array}{l}\text { Отопление и водоснабжение (включая } \\
\text { обслуживание печей, котлов, отопительных } \\
\text { установок и каминов) }\end{array}$ \\
\hline & K_1320 & $\begin{array}{l}\text { Другие конкретные виды деятельности, } \\
\text { связанные с уборкой и содержанием жилых } \\
\text { помещений и прилегающей территории }\end{array}$ \\
\hline & K_1330 & $\begin{array}{l}\text { Перестройка собственными силами, } \\
\text { обслуживание и ремонт жилых помещений, } \\
\text { хозяйственных построек, наружных помещений } \\
\text { собственными силами }\end{array}$ \\
\hline & K_1340 & $\begin{array}{l}\text { Установка, обслуживание и ремонт личных } \\
\text { вещей и предметов домашнего обихода }\end{array}$ \\
\hline & K_1350 & $\begin{array}{l}\text { Обслуживание и мелкий ремонт транспортных } \\
\text { средств }\end{array}$ \\
\hline & K_1360 & $\begin{array}{l}\text { Прочие конкретные виды деятельности, } \\
\text { связанные с отделкой, обслуживанием и мелким } \\
\text { ремонтом собственными силами }\end{array}$ \\
\hline $\begin{array}{l}\text { 5. Уход за газонами и } \\
\text { садами }\end{array}$ & K_1300 & Уход за садом, огородом, газонами и др. \\
\hline $\begin{array}{l}\text { 6. Управление } \\
\text { домохозяйством (включая }\end{array}$ & K_1410 & $\begin{array}{l}\text { Прочие виды работ по ведению домашнего } \\
\text { хозяйства }\end{array}$ \\
\hline $\begin{array}{l}\text { финансы, планирование и } \\
\text { др.) }\end{array}$ & K_1540 & $\begin{array}{l}\text { Неоплачиваемые бытовые услуги, не отнесенные } \\
\text { к другим категориям }\end{array}$ \\
\hline $\begin{array}{l}\text { 7. Уход за домашними } \\
\text { животными (не } \\
\text { ветеринарный уход) }\end{array}$ & K_1420 & Уход за домашними питомцами \\
\hline \multirow[t]{10}{*}{ 8. Покупка товаров и услуг } & K_822 & $\begin{array}{lcc}\text { Приобретение } & \text { материальных } & \text { ресурсов для } \\
\text { производства } & \text { продукции } & \text { (изготовления } \\
\text { изделий), не являющейся первичной (для себя) }\end{array}$ \\
\hline & K_1430 & $\begin{array}{l}\text { Поиск и приобретение потребительских товаров } \\
\text { в торговых точках }\end{array}$ \\
\hline & K_1440 & $\begin{array}{l}\text { Поиск и приобретение товаров длительного } \\
\text { пользования в торговых точках }\end{array}$ \\
\hline & K_1450 & Приобретение товаров через сеть Интернет \\
\hline & K_1460 & $\begin{array}{l}\text { Прочие конкретные виды действий, связанные с } \\
\text { поиском в магазинах и приобретением товаров }\end{array}$ \\
\hline & K_1470 & $\begin{array}{l}\text { Поиски получение услуг в области ремонта и } \\
\text { технического обслуживания }\end{array}$ \\
\hline & K_1480 & Поиск и получение административных услуг \\
\hline & K_1490 & $\begin{array}{l}\text { Поиски личных услуг по уходу /медицинских } \\
\text { услуг (не для себя) }\end{array}$ \\
\hline & K_1510 & Поиски и получение услуг по уходу за детьми \\
\hline & $\mathrm{K} \_1520$ & $\begin{array}{l}\text { Прочие конкретные виды поиска/использования } \\
\text { бытовых услуг }\end{array}$ \\
\hline \multirow[t]{4}{*}{ 9. Уход за детьми } & K_1550 & Уход за детьми/физический уход \\
\hline & K_1560 & Обучение, подготовка детей, общение \\
\hline & K_1570 & $\begin{array}{ll}\text { Сопровождение } & \text { детей } \\
\text { передвижений) } & \end{array}$ \\
\hline & K_1580 & Присмотр за детьми (пассивный уход) \\
\hline \multirow{6}{*}{$\begin{array}{l}\text { 10. Уход за пожилыми } \\
\text { (включая волонтерскую } \\
\text { деятельность) }\end{array}$} & K_1590 & Уход за взрослыми/физический уход \\
\hline & K_-1591 & Беседы, общение \\
\hline & K_1600 & Сопровождение взрослых (кроме передвижений) \\
\hline & K_1620 & $\begin{array}{l}\text { Оказание неоплачиваемых услуг по уходу за } \\
\text { членами домохозяйства, не отнесенных к другим } \\
\text { категориям }\end{array}$ \\
\hline & K_1630 & $\begin{array}{l}\text { Неоплачиваемая } \\
\text { домохозяйствам }\end{array}$ \\
\hline & K_1640 & Организованные общественные услуги \\
\hline
\end{tabular}




\begin{tabular}{|c|c|c|}
\hline $\begin{array}{c}\text { Группа видов деятельности } \\
\text { (согласно Методологии) }\end{array}$ & $\begin{array}{l}\text { Код вида деятельности } \\
\text { (согласно Опросу) }\end{array}$ & $\begin{array}{l}\text { Наименование вида деятельности } \\
\text { (согласно Опросу) }\end{array}$ \\
\hline & K_1650 & $\begin{array}{l}\text { Работа на добровольных началах на организацию } \\
\text { (не ориентированная непосредственно на } \\
\text { отдельных лиц) }\end{array}$ \\
\hline & K_1660 & $\begin{array}{l}\text { Работа на добровольных началах по линии } \\
\text { организаций (непосредственно в } \\
\text { отдельных лиц) }\end{array}$ \\
\hline & K_1670 & $\begin{array}{l}\text { Посещение встреч и собраний и прочие } \\
\text { социальные виды деятельности }\end{array}$ \\
\hline & K_1680 & $\begin{array}{l}\text { Взаимосвязанные виды деятельности: прочие } \\
\text { услуги обществу }\end{array}$ \\
\hline & & Услуги обществу и помощь другим \\
\hline & K_1700 & $\begin{array}{l}\text { домохозяйствам, не отнесенные к другим } \\
\text { категориям }\end{array}$ \\
\hline & K_794 & $\begin{array}{l}\text { Изготовление лечебных и санитарных средств из } \\
\text { растительного сырья, лекарственных растений } \\
\text { (для себя) }\end{array}$ \\
\hline \multirow{4}{*}{$\begin{array}{l}\text { 11. Передвижения } \\
\text { (связанные с деятельностью } \\
\text { по уходу и закупкой товаров } \\
\text { и услуг) }\end{array}$} & K_870 & $\begin{array}{l}\text { Передвижения, связанные с п производством } \\
\text { продукции, не являющейся первичной (для себя) }\end{array}$ \\
\hline & K_1530 & $\begin{array}{l}\text { Передвижения, связанные с } \\
\text { неоплачиваемых бытовых услуг }\end{array}$ \\
\hline & K_1610 & $\begin{array}{l}\text { Передвижения, связанные с } \\
\text { неоплачиваемых услуг по уходу за членем } \\
\text { домохозяйства }\end{array}$ \\
\hline & K_1690 & $\begin{array}{l}\text { Передвижения, связанные с оказанием услуг } \\
\text { обществу и помощи другим домохозяйствам }\end{array}$ \\
\hline
\end{tabular}




\title{
AN ESTIMATION OF HOUSEHOLD TIME TRANSFERS WITHIN HOUSEHOLDS
}

\author{
IRINA KALABIKHINA, ZHADRA SHAIKENOVA
}

\begin{abstract}
This article is devoted to the study of the distribution of time transfers in Russian households, the determination of the roles of women and men in the production and consumption of household services, and the assessment of "invisible" domestic labor. The study is based on the methodology developed in the framework of the UN National Transfer Accounts Project. As a result of the research we have found an asymmetry of the household duties distribution function between males and females. An empirical dataset has shown that females produce on average almost 3 hours per day more time transfers than males. Thus, females between the ages of 20 and 80 years old provide housekeeping services for the entire household. When household chores are included, a woman's ordinary 8-hour working day may be up to $40 \%$ longer. The traditional conclusions about the greater contribution of women both to the care economy and to housekeeping are supported by original conclusions about the age peaks for men and women in the production and consumption of time transfers. A matrix of intergenerational and intergender time transfers was constructed. The volume of "invisible" domestic labor was 25.3\% of GDP in 2014.
\end{abstract}

Key words: time transfers, time use, unpaid work, gender inequality, housekeeping, the economy of care

IRINA KALABIKHINA (ikalabikhina@yandex.ru), Lomonosov Moscow STATE UNIVERSITY, RUSSIA.

ZhadRa Shaikenova (shaikenova@mail.ru), Lomonosov Moscow State University, Russia.

DATE RECEIVED: OCTOBER 2018.

\section{REFERENCES}

Albertini M., M. Kohli, C. Vogel (2007). Intergenerational transfers of time and money in European families: common patterns - different regimes? // Journal of European Social Policy. 17: 319-334.

Anxo D., L. Flood, L. Mencarini, A. Pailhé, A. Solaz, M.L. Tanturri (2007). Time allocation between work and family over the life-cycle: A comparative gender analysis of Italy, France, Sweden and the United States // IZA DP. 3193: 1-35.

Apps P., R. Rees (2005). Gender, time use and public policies over the life-cycle // IZA. 1855: 136.

Attias-Donfut C., F.-C. Wolff (2000). Complementarity between private and public transfers // The Myth of Generational Conflict / S. Arber, C. Attias-Donfut, eds. London: Routledge: 4768.

Becker G.S. (1965). A theory of the allocation of time // The Economic Journal. 75(299): 493517.

Bianchi S.M. (2011). Family change and time allocation in American families // The Annals of the American Academy of Political and Social Science. 638: 21-44.

Brandt M., K. Haberkern, M. Szydlik (2009). Intergenerational help and care in Europe // European Sociological Review. 25(5): 585-601.

Choi H. (2011). Parents' health and adult children's subsequent working status: A perspective of intergenerational transfer and time allocation // Journal of Family and Economic Issues.

32(3): 493-507. 
Clark C. (1958). The economics of housework // Bulletin of the Oxford institute of Statistics: 205-211.

Deloach S.B., A.L. Hoffman (2002). Russia's second shift: is housework hurting women's wages? // Atlantic Economic Journal. 30(4): 422-32.

Donehower G. (2014). Incorporating gender and time use into NTA: Estimating NTA and national time transfer accounts by sex. URL: http://www.ntaccounts.org/web/nta/show/Gender,\%20Time\%20use (дата обращения: 12.03.2018).

Dukhovnov D., E. Zagheni (2015). Who takes care of whom in the United States? Time transfers by age and sex // Population and Development Review 41(2): 183-206.

Fitzgerald J. (1990). Measuring the value of household output: a comparison of direct and indirect approaches // Review of Income and Wealth. Series 36. 2: 129-141.

Giannelli G., L. Mangiavacchi, L. Piccoli (2011). GDP and the value of family caretaking: How much does Europe care? // Applied Economics. 44(16): 2111- 2131.

Gvozdeva G.P. (2000). Neoplachivaemyy trud kak faktor adaptatsii rossiyan v period krizisa [Unpaid work as a factor in the adaptation of Russians during a crisis] // Vestnik NGU [Bulletin of the NSU]. Seriya: Sotsial'no-ekonomicheskie nauki [Series: Socio-Economic Sciences]. 1. 1: 55-68.

Hamdad M. (2003). Valuing households' unpaid work in Canada, 1992 and 1998: Trends and sources of change // Statistics Canada Economic Conference: 1-14.

Hochschild A. (1989). The second shift. Working parents and the revolution at home // New York: Viking. 322 p.

Human Development Report (2006). Beyond scarcity: Power, poverty and the global water crisis. United Nations Development Programme (UNDP). URL:

http://hdr.undp.org/sites/default/files/reports/267/hdr06-complete.pdf (accessed: 29.09.2018).

ICATUS (2016). United Nations Statistics Division. International Classification of Activities for Time Use Statistics 2016.

Itogi pilotnogo vyborochnogo obsledovaniya ispol'zovaniya (byudzheta) vremeni naseleniem [Results of a pilot sample of time use survey] (2010). Moscow: Rosstat: 7-78.

Kalabikhina I.E. (2004). Vremya na domashnyuyu rabotu: faktory nagruzki [Time for homework: load factors] // Materialy nauchnoi konferentsii [Materials of the scientific conference]. Lomonosovskie chteniya 2004-2006. 12-15 aprelya [Lomonosov readings. April 12-15]. Moscow: TEIS.

Kalabikhina I.E. (2011). Gendernyy perekhod i kachestvo zhizni [Gender transition and quality of life] // Uroven' zhizni naseleniya regionov Rossii [The standard of living of the population of Russian regions]. 8: 42-48.

Kuznets S., L. Epstein, E. Jenks (1944). National Income and its Composition // National Bureau of Economic Research. 388 p.

Landefeld J.S., B.M. Fraumeni, C.M. Vojtech (2009). Accounting for household production: A prototype satellite account using the American time use survey // Review of Income and Wealth. Series 55(2): 205-225.

Layard R., A. Clark, F. Cornaglia, N. Powdthavee, J. Vernoit (2014). What predicts a successful life? A life-course model of wellbeing // Economic Journal. 124: 720-738. 
Leopold T., M. Raab (2010). Intergenerational exchange of time and money: Short-term reciprocity in parent-child relationships // National Council on Family Relations: 105-119.

Lewis J. (1992). Gender and the development of welfare regimes // Journal of European Social Policy. 2(3): 159-173.

Löfmark M.H. (2007). Gender and time allocation differences in Taganrog, Russia // International Journal of Time Use Research. 4. 1: 69-92.

McDonald P. (2000). Gender equity in theories of fertility transition // Population and Development Review. 26(3): 427-439.

Mitchell W., W.I. King, F.R. Macaulay, C.W. Knauth (1921). Income in the United States: its Amount and Distribution // National Bureau of Economic Research. 154 p.

Patrushev V.D., V.A. Artemov, O.V. Novokhatskaya (2001). Izuchenie byudzhetov vremeni v Rossii XX v. [Studying time use in Russia in the 20th century] // Sotsiologicheskie issledovaniya [Sociological Studies]. 6: 112-120.

Prudenzky G.A. (1972). Problemy rabochego i vnerabochego vremeni [Problems of working and nonworking time]. Moscow: Nauka. 335 p.

Reid M. (1934). Economics of Household Production // New York: Wiley. 424 p.

Riley L.D., C.P. Bowen (2005). The sandwich generation: Challenges and coping strategies of multigenerational families // The Family Journal. 13(1): 52-58.

Sotsiologiya v Rossii [Sociology in Russia] (1996). Uchebnik [Textbook] / V.A. Yadov, ed. Moscow: Publishing House "Na Vorobyovyh". 700 p.

Strumilin S.G. (1957). Problemy ekonomiki truda [Problems of Labor Economics]. Moscow: Gospolitizdat. 735 p.

Szydlik M. (2004). Inheritance and inequality: theoretical reasoning and empirical evidence // European Sociological Review. 20: 31-45.

Temkina A.A., A. Rotkirch (2002). Sovetskie gendernye kontrakty i ikh transformatsiya v sovremennoy Rossii [Soviet gender contracts and their transformation in contemporary Russia] // Sotsiologicheskie issledovaniya [Sociological Research]. 11: 4-14.

Vargha L., R.I. Gál, M.O. Crosby-Nagy (2017). Household production and consumption over the life cycle: National Time Transfer Accounts in 14 European countries // Demographic Research. 36(32): 905-944. URL:https://www.demographicresearch.org/volumes/vol36/32/36-32.pdf (accessed: 29.09.2018).

Vyborochnoe nablyudenie ispol'zovaniya sutochnogo fonda vremeni naseleniem Rossiyskoy Federatsii [Selective supervision of use of daily fund of time by the population] (2015). Federal'naya sluzhba gosudarstvennoy statistiki [Federal State Statistics Service]. URL: http://www.gks.ru/free_doc/new_site/population/urov/sut_fond/survey0/index.html (accessed: 12.03.2018).

Webber D. (2017). Measuring and valuing unpaid household service work // Workshop on Gender Statistics (Belgrade, Serbia, 27-28 November): 1-35. 